\title{
Overexpression of Il6 leads to hyperinsulinaemia, liver inflammation and reduced body weight in mice
}

\author{
S. Franckhauser • I. Elias • V. Rotter Sopasakis • \\ T. Ferré • I. Nagaev • C. X. Andersson • J. Agudo • \\ J. Ruberte • F. Bosch $\cdot$ U. Smith
}

Received: 9 October 2007 / Accepted: 21 February 2008 / Published online: 24 April 2008

(C) Springer-Verlag 2008

\begin{abstract}
Aims/hypothesis IL-6 is released by the adipose tissue and increased circulating levels in obesity are associated with hyperinsulinaemia and insulin resistance. Short-term experiments suggest that increased IL-6 release by the skeletal muscle following exercise may improve insulin sensitivity.

Methods In order to examine the effect of chronically elevated IL-6 levels, we overexpressed Il6 in skeletal muscle in mice using an electro-transfer procedure.

Results Circulating IL-6 levels were increased and the animals rapidly lost both weight and body fat, but food intake was unchanged, which is consistent with the finding

S. Franckhauser, I. Elias and V. Rotter Sopasakis contributed equally to this study.
\end{abstract}

Electronic supplementary material The online version of this article (doi:10.1007/s00125-008-0998-8) contains supplementary material, which is available to authorised users.

S. Franckhauser · I. Elias · T. Ferré · J. Agudo •

J. Ruberte $\cdot$ F. Bosch

Center of Animal Biotechnology and Gene Therapy,

Department of Biochemistry and Molecular Biology,

School of Veterinary Medicine,

Universitat Autònoma de Barcelona,

Bellaterra CIBERDEM-ISCIII, Spain

V. Rotter Sopasakis · I. Nagaev · C. X. Andersson • U. Smith

The Lundberg Laboratory for Diabetes Research,

Center of Excellence for Metabolic and Cardiovascular Research,

Department of Molecular and Clinical Medicine,

Sahlgrenska Academy at University of Gothenburg,

Gothenburg, Sweden

U. Smith $(\bowtie)$

Department of Molecular and Clinical Medicine,

Sahlgrenska University Hospital,

SE-413 45 Gothenburg, Sweden

e-mail: ulf.smith@medic.gu.se that IL-6 increased energy expenditure. Insulin levels were inappropriately elevated and combined with hypoglycaemia in spite of reduced 2-deoxy-D-glucose uptake by skeletal muscle. Insulin-stimulated glucose uptake by skeletal muscles ex vivo was reduced, probably due to the decreased amounts of glucose transporter (GLUT)-4. Beta cell insulin content was increased, while apparent beta cell mass was unchanged. Circulating serum amyloid A cluster levels were increased tenfold due to a pronounced proinflammatory state in the liver with infiltration of inflammatory cells. However, no liver steatosis was found, which may be accounted for by concomitant AMP kinase activation.

Conclusions/interpretation Chronically elevated IL-6 levels lead to inappropriate hyperinsulinaemia, reduced body weight, impaired insulin-stimulated glucose uptake by the skeletal muscles and marked inflammation in the liver. Thus, the pleiotrophic effects of chronically elevated IL-6 levels preclude any obvious usefulness in treating obesity or its associated metabolic complications in man, despite the fact that weight reduction may be expected.

Keywords AMPK · AMP kinase - Cytokines · Inflammation · Insulin · Insulin resistance ·

Insulin secretion $\cdot$ Obesity

$\begin{array}{ll}\text { Abbreviations } \\ \text { AMPK } & \text { AMP kinase } \\ \mathrm{CMV} & \text { cytomegalovirus } \\ \mathrm{CoA} & \text { coenzyme A } \\ 2 \text {-DG } & \text { 2-deoxy-D- }\left[1-{ }^{3} \mathrm{H}\right] \text { glucose } \\ \mathrm{GFP} & \text { green fluorescent protein } \\ \mathrm{GLUT} & \text { glucose transporter } \\ \mathrm{PKB} & \text { protein kinase B } \\ \mathrm{VO}_{2} & \text { oxygen consumption }\end{array}$




\section{Introduction}

IL-6 is a pluripotent cytokine secreted by various tissues and cells, such as immune cells, endothelial cells, myocytes and adipose cells $[1,2]$, that mediate inflammatory and stress-induced responses. Circulating and adipose tissue IL-6 levels are increased in patients with obesity, insulin resistance and type 2 diabetes [3-9], the increased level correlating with degree of insulin resistance measured as insulin-stimulated glucose uptake [7-9]. Although difficult to firmly prove, it has been suggested that the increased plasma concentrations of IL- 6 in patients with type 2 diabetes are an indicator of the increased fat mass rather than insulin resistance as such [10]. However, it is well established that the adipose tissue is an important source of IL-6 production in man [5].

Several experimental studies in adipose and liver cells $[6,11-14]$, as well as animal experiments where IL-6 has been chronically infused, have shown that IL-6 impairs insulin sensitivity and action in these cells and also induces insulin resistance in vivo $[14,15]$. However, insulin-like effects in skeletal muscle cells, associated with AMP kinase (AMPK) activation, have also been shown [16-19]. Taken together, many experimental studies have shown that chronic exposure to IL-6 induces insulin resistance with the possible exception of skeletal muscle. However, the final outcome in terms of whole-body insulin sensitivity is quite controversial.

The effect of short-term IL-6 treatment on whole-body insulin action and glucose homeostasis has been studied in humans and rodents. The results are contradictory, with some improvement, no effect and deterioration having been reported [14, 15, 18]. IL-6 may also be involved in the regulation of adipose tissue expansion and energy expenditure. IL-6 knockout mice have been reported in some [20], but not all [21] studies to develop maturity-onset obesity, which proved reversible by intra-cerebro-ventricular, but not peripheral IL-6 infusion [22]. General IL-6 overproduction has been shown to produce cachexia [23]. Moreover, it has been reported that IL-6 may have lipolytic effects on adipocytes both in vitro and in vivo, increase fat oxidation and reduce the expression and activity of lipoprotein lipase [24-26].

These metabolic effects have been suggested to be important in the post-exercise period, since IL-6 is also produced by skeletal muscles during exercise $[27,28]$ and released to the circulation at high levels. Glucose ingestion during exercise decreases IL-6 release by the contracting muscles, suggesting that IL-6 production by skeletal muscle may be regulated by substrate availability [29]. However, it was recently demonstrated that IL- 6 is not the mediator of the exercise-induced increase in lipolysis and fat oxidation [30].
Thus, while many studies have shown a link between chronically elevated IL-6 levels and insulin resistance, other, and importantly, short-term studies have suggested that IL-6 may have no effect or even a beneficial effect. In fact, it has even been suggested that IL- 6 released by skeletal muscle may be an important mediator of the positive effects of exercise including the improvement in insulin sensitivity [28]. In order to examine the effect of chronically elevated IL- 6 production by skeletal muscle on glucose homeostasis and phenotype, mice were electrotransferred with a chimeric gene carrying the cytomegalovirus (CMV) promoter and Il6 cDNA.

\section{Methods}

Treatment of mice We used 6 to 8-week-old C57B1/ 6JOlaHsd (Harlan Interfauna Iberica, Sant Feliu De Codines, Spain) male mice for in vivo gene transfer studies. Mice had free access to a standard diet (Panlab, Barcelona, Spain) and were maintained under a $12 \mathrm{~h}$ light-dark cycle (lights on at 08:00 hours). When stated, mice were fasted for $16 \mathrm{~h}$. An indirect open circuit calorimeter (Oxylet; Panlab, Cornella, Spain) was used to monitor oxygen consumption $\left(\mathrm{VO}_{2}\right)$, carbon dioxide production and food intake in four metabolism chambers simultaneously. Mice were acclimatised to the metabolism chambers for $24 \mathrm{~h}$ and data were collected for $3 \mathrm{~min}$ at $15 \mathrm{~min}$ intervals in each cage. Data were taken from the light cycle (basal state) or from a continuous $24 \mathrm{~h}$ light-dark cycle (total) and adjusted for body weight. The measurements were performed 7 and 15 days after gene transfer. Animals were anaesthetised and killed, and samples (tibialis cranealis, quadriceps and gastrocnemius muscles, adipose tissue and liver) were taken between 09:00 and 11:00 hours, and immediately frozen. For metabolite assays, liver and skeletal muscle biopsies were obtained from anaesthetised mice, freezeclamped, placed immediately in liquid $\mathrm{N}_{2}$ and kept at $-80^{\circ} \mathrm{C}$ until analysis.

All experimental procedures involving mice were approved by the Ethics and Experimental Animal Committee of the Universitat Autònoma de Barcelona.

In vivo gene transfer For electro-transfer studies, pCMVIL-6 was purified using a plasmid kit (Endofree; Qiagen, Crawley, UK) and dissolved in $0.9 \% \mathrm{NaCl}$. The mice were anaesthetised with ketamine/xylazine and $2 \mathrm{~h}$ before electro-transfer muscles were pretreated with hyaluronidase (10 U/muscle) [31]. Afterwards, naked pCMV0-IL-6 was injected into tibialis cranealis, gastrocnemius and quadriceps muscles of both hind limbs. We established that the optimal quantity of plasmid to inject in order to get good 
expression in the skeletal muscles, which also increased the circulating level of IL-6, was $100 \mu \mathrm{g}$ DNA per mouse. Ten pulses of $20 \mathrm{~ms}$ each were applied to each muscle at $175 \mathrm{~V} / \mathrm{cm}$ and $2 \mathrm{~Hz}$, using an electroporator (ECM 830; BTX, Holliston, MA, USA). The control animals followed the same procedure after injection of saline and empty vector.

Enzyme, metabolite and hormone assays Tissue triacylglycerol content was determined by extracting total lipids from liver and skeletal muscle (gastrocnemius) samples with chloroform-methanol (2:1, vol./vol.) as described [32]. Triacylglycerol was then quantified spectrophotometrically using an enzymatic assay kit (GPO-PAP; Horiba-ABX, Montpellier, France). Glycogen and lactate were determined in skeletal muscle and liver from fed mice as previously described [33]. Serum glucose was measured enzymatically (hexokinase method; Horiba-ABX) as well as with an analyser (Glucometer Elite; Bayer, Leverkusen, Germany). Serum NEFA was measured by the acylcoenzyme A (CoA) synthase and acyl-CoA oxidase methods (Wako Chemicals, Neuss, Germany). Serum glycerol concentration was determined enzymatically (Randox Lab, Crumlin, UK). Insulin levels were measured by radioimmunoassay (CIS, Biointernational, Gif-Sur-Yvette, France). Alanine amino transferase activity was measured in serum using an enzymatic kit (Horiba-ABX). All other biochemical parameters were determined using an analyser (Pentra 400: Horiba-ABX). Leptin concentration was determined in serum with an enzyme-linked immunoabsorbent assay kit (Crystal Chemical, Chicago, IL, USA), adiponectin by a radioimmunoassay (Linco Research, St Charles, MO, USA), and both IL-6 and amyloid A concentrations by enzymelinked immunoabsorbent assay (Assay Designs, Ann Arbor, MI, USA and Biosource International, Camarillo, CA, USA respectively). To determine pancreatic insulin content, whole pancreases were removed from the mice, weighed and homogenised in twenty volumes cold acidic ethanol $(75 \%$ [vol./vol.] ethanol, $1.5 \%$ [vol./vol] concentrated $\mathrm{HCl}$ ) followed by $48 \mathrm{~h}$ of agitation at $4{ }^{\circ} \mathrm{C}$. Insulin was quantified in the supernatant fractions.

In vivo glucose utilisation index An intravenous injection of $3.7 \times 10^{4} \mathrm{~Bq}$ of the non-metabolisable glucose analogue 2-deoxy-D-[1- $\left.{ }^{3} \mathrm{H}\right]$ glucose (2-DG; Amersham Pharmacia Biotech, Piscataway, NJ, USA) was administered to fed mice. The specific blood 2-DG clearance was determined by the Somogyi procedure with $25 \mu$ l blood samples (tail vein) obtained 1, 10, 20 and $30 \mathrm{~min}$ after injection. Skeletal muscle (gastrocnemius and quadriceps) samples were removed $30 \mathrm{~min}$ after injection. The glucose utilisation index was determined by measuring the accumulation of radiolabelled compounds [34]. The amount of 2-DG-6phosphate/mg protein was divided by the integral of the concentration ratio of 2-DG to unlabelled glucose measured. Since values were not corrected by a 'discrimination constant' for 2-DG in glucose metabolic pathways, the results are expressed as the index of glucose utilisation.

Glucose and insulin tolerance tests For the glucose tolerance test, awake control and transgenic mice, fasted overnight $(16 \mathrm{~h})$ with free access to water, were given an intraperitoneal injection of glucose $(1 \mathrm{~g} / \mathrm{kg}$ body weight $)$. Blood samples were obtained from the tail vein before the glucose injection and at $15,30,45$ and $60 \mathrm{~min}$ postinjection, and glucose and insulin concentrations measured. For the insulin tolerance test, insulin $(0.375 \mathrm{IU} / \mathrm{kg}$ body weight; Humulin regular, Eli Lilly, Indianapolis, IN, USA) was injected intraperitoneally into awake, fed control and transgenic mice.

Glucose uptake ex vivo 2-DG uptake was measured as previously described [35] in mice starved overnight. Isolated soleus muscles were first incubated for $30 \mathrm{~min}$ at $37^{\circ} \mathrm{C}$ in $2 \mathrm{ml}$ of $\mathrm{KRBH}$ buffer, $\mathrm{pH} 7.4$, with $20 \mathrm{mmol} / 1$ HEPES, $2 \mathrm{mmol} / 1$ pyruvate and $1 \%$ BSA, continuously gassed with $\mathrm{O}_{2}: \mathrm{CO}_{2}$ (95:5). Muscles were then incubated for $30 \mathrm{~min}$ in $2 \mathrm{ml}$ of fresh KRBH buffer containing or not insulin $(10 \mathrm{mU} / \mathrm{ml})$. A third incubation was conducted for $10 \mathrm{~min}$ with the same medium plus $0.5 \mathrm{mmol} / 12$ 2-[ $\mathrm{H}] \mathrm{DG}$ $\left(1.85 \times 10^{4} \mathrm{~Bq} / \mathrm{ml}\right)$. The muscles were washed for $20 \mathrm{~min}$ in ice-cold KRB solution, blotted, solubilised in $1 \mathrm{~mol} / 1 \mathrm{NaOH}$ at $70^{\circ} \mathrm{C}$ and then neutralised with $1 \mathrm{~mol} / \mathrm{l} \mathrm{HCI}$. Radioactivity in the samples was assessed by liquid scintillation counting and related to the protein concentration.

Histological analysis The epididymal fat pad and liver from control and transgenic mice were fixed for 12 to $24 \mathrm{~h}$ in formalin, embedded in paraffin and sectioned. Sections were stained with haematoxylin/eosin. For pancreas morphometric analysis, nine pancreatic sections from each individual mouse (three mice per group) were viewed with a microscope (Eclipse E800; Nikon, Tokyo, Japan). Images were obtained with a video camera connected to a colour monitor and to an image analyser (analySIS 3.0; Soft Imaging System, Lakewood, CO, USA). Islet mass was measured as previously described [36].

Immunohistochemistry on liver sections and flow cytometry analysis See Electronic supplementary material (ESM).

$m R N A$ analyses and immunoblotting The experimental procedures have been described previously [37]. For detailed information, see ESM.

Statistical analysis The data are expressed as the means \pm SEM. The significance of differences between data was 
analysed using the Student-Newmann-Keuls test. Differences were considered significant at $p<0.05$.

\section{Results}

IL-6 production is increased by electro-transfer of a CMVIL-6 chimeric gene into skeletal muscle Plasmid gene transfer with a good efficiency is achievable by intramuscular injection associated with electroporation and a previous intramuscular hyaluronidase treatment [31]. About $75 \%$ of muscle fibres were transfected by this method after the injection of a plasmid expressing green fluorescent protein (GFP) under the control of a CMV promoter (CMV-GFP; Fig. 1a).

To overexpress $I l 6$ in skeletal muscle, we constructed a plasmid containing a chimeric gene in which $I l 6$ cDNA expression is driven by a CMV promoter (Fig. 1b). The highest level of expression was reached 5 to 10 days after electro-transfer and, therefore, most parameters were measured after 1 to 2 weeks (Fig. 1c). A marked increase in skeletal muscle $I l 6$ mRNA levels was observed 7 days after electro-transfer (Fig. 1d, Table 1) and this increase was also reflected by elevated circulating IL-6 levels, reaching a maximum at 7 to 15 days after electro-transfer (Fig. 1e). Serum IL-6 levels were about five- to eightfold higher than those generally seen in man after strenuous exercise, but similar to those seen in different states of chronic inflammation $[27,28]$.

\section{IL-6 overproduction leads to body weight loss and decreased}

fat mass Mice overproducing IL-6 showed a body weight reduction of about $20 \%$ in 7 days and remained lean for at least 30 days after electro-transfer (Fig. 2a). This decrease in body weight was associated with a decrease in fat pad weight and adipocyte size (Fig. 2b,c). The mice developed a slightly reduced muscle mass (quadriceps weight $252 \pm 12$ vs $229 \pm 14 \mathrm{mg}, p<0.05$ in control and IL- 6 mice, respectively). The food intake of IL-6 mice was similar to control mice (data not shown), while the total daily respiratory quotient was reduced (control $0.997 \pm 0.013, n=3$ vs IL-6 $0.911 \pm 0.011, n=5 ; p=0.0074)$, suggesting increased fat oxidation. Both $V \mathrm{O}_{2}$ and total daily energy expenditure were significantly increased in IL-6 mice by about $15 \%$ $(p<0.05)$, but there was no difference in spontaneous activity (data not shown).

Skeletal muscle IL-6 overabundance is associated with hypoglycaemia and inappropriate hyperinsulinaemia Both serum NEFA and glycerol levels were greatly decreased in IL-6 mice (Fig. 2d,e). Circulating lactate and triacylglycerol concentrations were decreased (Fig. 2f,g), as was leptin (Fig. 2h). Adiponectin levels were also greatly reduced
(Fig. 2i), in contrast to what would be expected in view of the reduced adipose mass and small fat cell size.

Blood glucose levels were measured in both fed and fasted conditions. Mice overproducing IL-6 had a significant reduction in both fed (33\% decrease) and fasted (36\% decrease) (Fig. 3a). Moreover, post-absorptive insulin levels

a

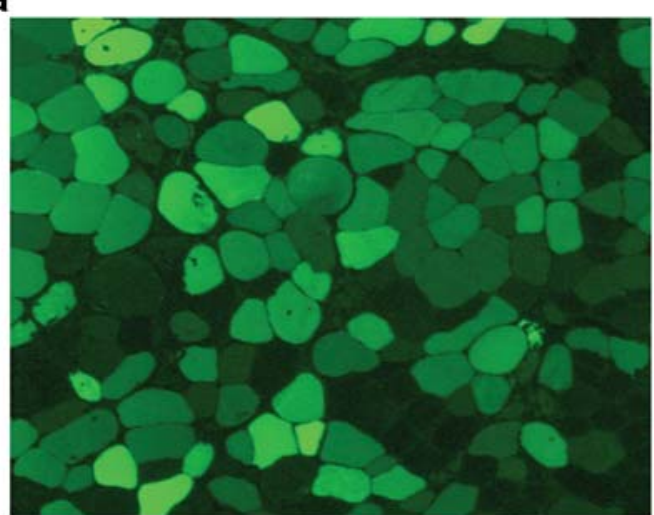

b

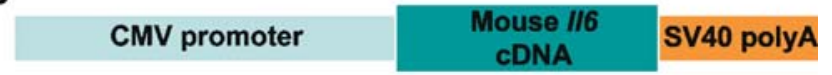

\section{Body weight

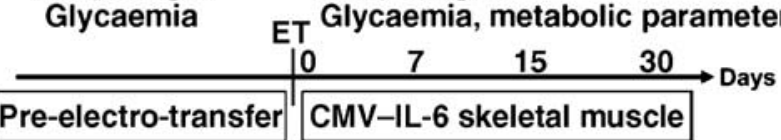

d e
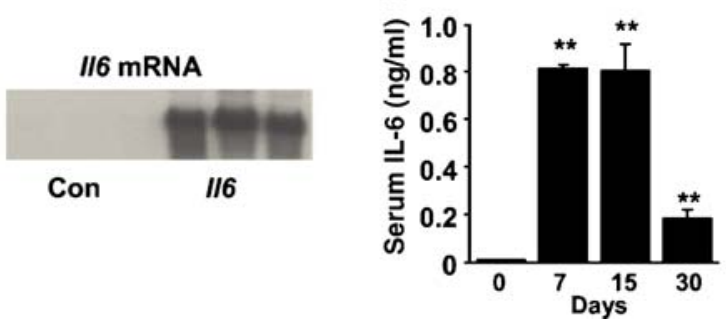

Fig. 1 CMV-IL-6 chimeric gene electro-transfer to skeletal muscle leads to increased circulating IL-6 levels. a GFP expression in tibialis cranealis muscle of control mice electro-transfected with CMV-GFP plasmid. Fifteen days after gene transfer, GFP expression was analysed in tissue sections by fluorescence microscopy $(\times 200)$. b Schematic representation of CMV-IL-6 chimeric gene. A DNA fragment containing the $\mathrm{CMV}$ promoter was fused to the coding sequence of the mouse Il-6 cDNA and to the simian virus polyadenylation signal (SV40 polyA). c Experimental design. Body weight and glycaemia from all the mice were recorded before electrotransfer (ET). ET to skeletal muscle of mice 8 weeks of age was performed at day 0 with CMV-IL-6 plasmid (IL-6) or saline solution (Con) and metabolic parameters were measured between day 7 and day 30. d Representative northern blot of RNA from quadriceps e Circulating levels of IL-6. Mouse IL-6 concentrations were measured in serum from CMV-IL-6 electro-transfected mice 7, 15 and 30 days after gene transfer. Data represent the mean \pm SEM of at least six animals for each group. ${ }^{* *} p<0.01$ 
Table 1 Gene expression in Il6-overexpressing mice relative to control mice

\begin{tabular}{|c|c|c|}
\hline Parameter & Change & Fold change \\
\hline \multicolumn{3}{|c|}{ Gene in liver } \\
\hline Pckl & Decrease & 0.57 \\
\hline Fasn & Decrease & 0.62 \\
\hline Il6 & Increase & 1.9 \\
\hline Socs 3 & Increase & 2.7 \\
\hline Stat3 & Increase & 2.3 \\
\hline $\operatorname{Tn} f$ & Increase & 11.3 \\
\hline Saa2 & Increase & 598 \\
\hline Saa3 & Increase & 29 \\
\hline Ccl2 & Increase & 3.6 \\
\hline Itgam & Increase & 25 \\
\hline $\operatorname{Irs} 1$ & Decrease & 0.6 \\
\hline $\operatorname{Irs} 2$ & n.d. & 1.1 \\
\hline Adipor2 & Decrease & 0.72 \\
\hline Ppargcla & Decrease & 0.52 \\
\hline \multicolumn{3}{|c|}{ Gene in skeletal muscle } \\
\hline Il6 & Increase & 3,000 \\
\hline Ilbra & Increase & 3.6 \\
\hline $\operatorname{Socs} 3$ & Increase & 12.5 \\
\hline Socs 1 & n.d. & 1 \\
\hline Slc2a4 & Decrease & 0.7 \\
\hline Irs 1 & n.d. & 0.8 \\
\hline $\operatorname{Irs} 2$ & n.d. & 1 \\
\hline Adipor1 & Decrease & 0.8 \\
\hline Adipor2 & Decrease & 0.8 \\
\hline Foxc2 & Increase & 2.4 \\
\hline Ucp2 & Increase & 5 \\
\hline
\end{tabular}

n.d., no significant difference

All other changes were statistically significant $(p<0.05)$ and relative to control mice $(=1)$

were increased by about twofold in IL-6 mice in spite of the hyperglycaemia (Fig. 3b).

In vivo insulin release in response to a glucose injection was assessed following an intraperitoneal glucose injection. Blood glucose levels remained lower in IL-6 than in control mice (Fig. 3c). At 2 and $5 \mathrm{~min}$ after glucose injection, insulin release into the circulation was also higher in fasting IL-6 mice (Fig. 3d). Moreover, pancreatic insulin content was increased in IL-6 mice (Fig. 3e). However, beta cell mass was not apparently altered by IL-6 overabundance (Fig. 3f). Taken together, these data show that insulin synthesis and secretion are markedly increased in Il6-overexpressing mice and that the normal glucose-insulin feed-back loop is disrupted, leading to hypoglycaemia.

High levels of circulating IL-6 lead to decreased skeletal muscle glucose uptake and GLUT-4 content The effect of IL-6 on skeletal muscle glucose uptake was measured by in vivo $2-\mathrm{DG}$ uptake. In spite of the ambient hyperinsulinae- mia, basal glucose uptake was reduced in IL- 6 mice both in quadriceps and gastrocnemius muscles (Fig. 4a).

We also examined 2-DG uptake by the isolated soleus muscle. Basal glucose uptake was unchanged, while the effect of insulin was markedly reduced (Fig. 4b). To examine the molecular mechanisms, we measured both GLUT-1 and GLUT-4 content in isolated plasma membranes before and after exposure to insulin. GLUT-4 content was reduced $\sim 50 \%$ under both conditions (Fig. 4c), while GLUT-1 was unchanged (data not shown). To determine whether insulin signalling was altered, we also examined the effect of insulin on serine phosphorylation of protein kinase B (PKB)/Akt, but saw no clear difference (not shown). Thus, the reduced glucose uptake in vivo seems to be accounted for by the reduced GLUT- 4 content in the skeletal muscle of IL- 6 mice.

The glycogen and lactate contents were not significantly altered in these muscles, whereas the triacylglycerol content was decreased $\sim 50 \%$ (Fig. $4 d-f$ ).

AMPK phosphorylation Previous studies have reported that IL-6 increases the phosphorylation of AMPK in several different cells [16-19]. Indeed, phosphorylated AMPK was markedly increased in the IL-6 mice, while gp130 was not altered (Fig. 4g).

Overproduction of IL-6 leads to systemic inflammation and decreased glucose production Hypoglycaemia combined with hyperinsulinaemia suggests reduced hepatic glucose production. This is also supported by the marked reduction in Pepck (also known as Pckl) mRNA levels (Table 1) and is also consistent with the decreased hepatic glucose 6-phosphate, glycogen and triacylglycerol content (Fig. 5a,c,d) in IL-6 mice. In contrast, glucokinase activity was increased, suggesting that glucose uptake by the liver may also be increased (not shown). However, there was no significant difference in hepatic lactate content between the mice (Fig. 5b).

Histological analysis of the liver showed that clear spaces in the cytoplasm representing glycogen vacuoles were absent in IL-6 mice, in agreement with the decrease in hepatic glycogen content (Fig. 5d,f). Both hepatic gene expression and circulating levels of serum amyloid $\mathrm{A}$, an inflammation marker of the liver, were markedly elevated in the IL-6 mice (Table 1, Fig. 5e). Moreover, a marked infiltration of cells was observed around the vessels (Fig. 5f,g).

To further characterise this infiltrate, liver biopsies were subjected to flow cytometry analysis (FACS). FACS analysis demonstrated that F4/80 (characteristic for monocytes and macrophages) positive cell number was increased in liver from mice treated with IL-6, whereas CD11bpositive cell number was not significantly increased (Fig. 6a). Immunohistological analysis of liver sections 
Fig. 2 Weight loss in mice with increased circulating IL-6 levels. a Body weight of CMV-IL-6 electro-transfected mice 7, 15 and 30 days after gene transfer. b Epididymal fat pad weight of saline solution (control, Con) and CMV-IL-6 (IL-6) electrotransfected mice 7 days after gene transfer. Data represent the mean \pm SEM of at least eight animals for each group. ${ }^{* *} p<$ 0.01 . c Representative sections of epididymal white adipose tissue from Con and CMV-IL-6 (IL-6) electro-transfected mice 7 days after gene transfer stained with haematoxylin/eosin $(\times 400)$. d NEFA, e glycerol, $\mathbf{f}$ triacylglycerol, $\mathbf{g}$ lactate, $\mathbf{h}$ leptin and $\mathbf{i}$ adiponectin levels in serum from fed mice 7 days after gene transfer with saline solution (Con) or CMV-IL-6 (IL-6) DNA. Data represent the mean \pm SEM of at least ten animals for each group. $* * p<0.01$

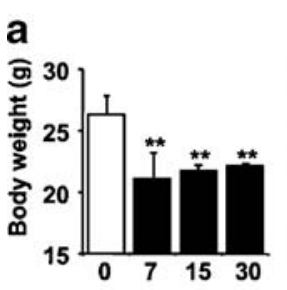

b c
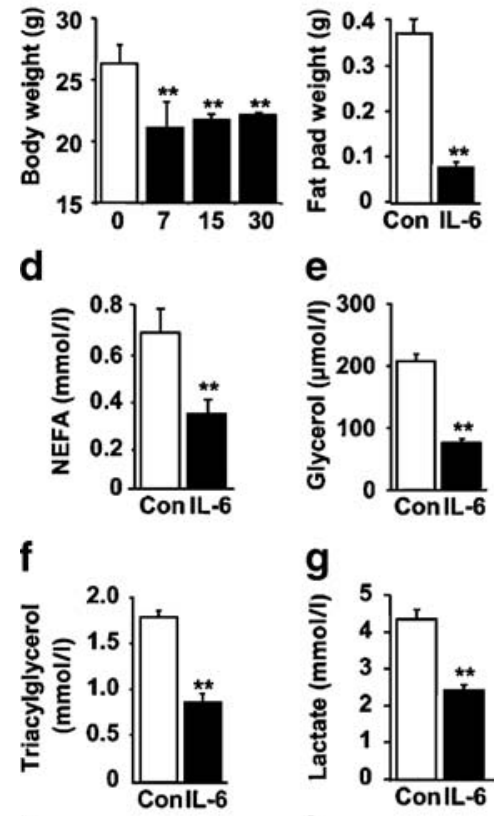

h
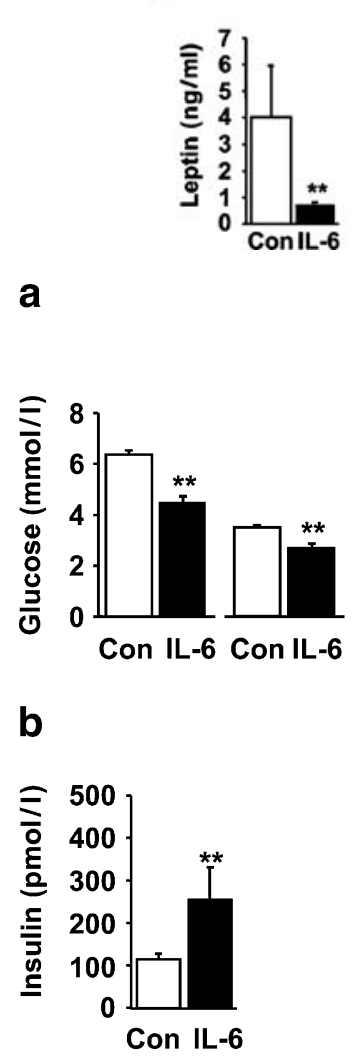

Fig. 3 Glucose homeostasis. a Blood glucose concentrations in fed or overnight-fasted mice and (b) serum insulin in fed mice were measured 7 days after gene transfer with saline solution (control, Con) or CMV-IL-6 (IL-6) DNA. Data represent the mean \pm SEM of at least ten animals for each group. ${ }^{* *} p<0.01$. c Blood glucose and $\mathbf{d}$ insulin levels in saline solution (control, white circles) and CMV-IL6 (black circles) electro-transfected mice after intraperitoneal injection of glucose (1 g/kg mouse). Seven days after gene transfer, mice were starved overnight and blood was collected by tail vein bleeding at c

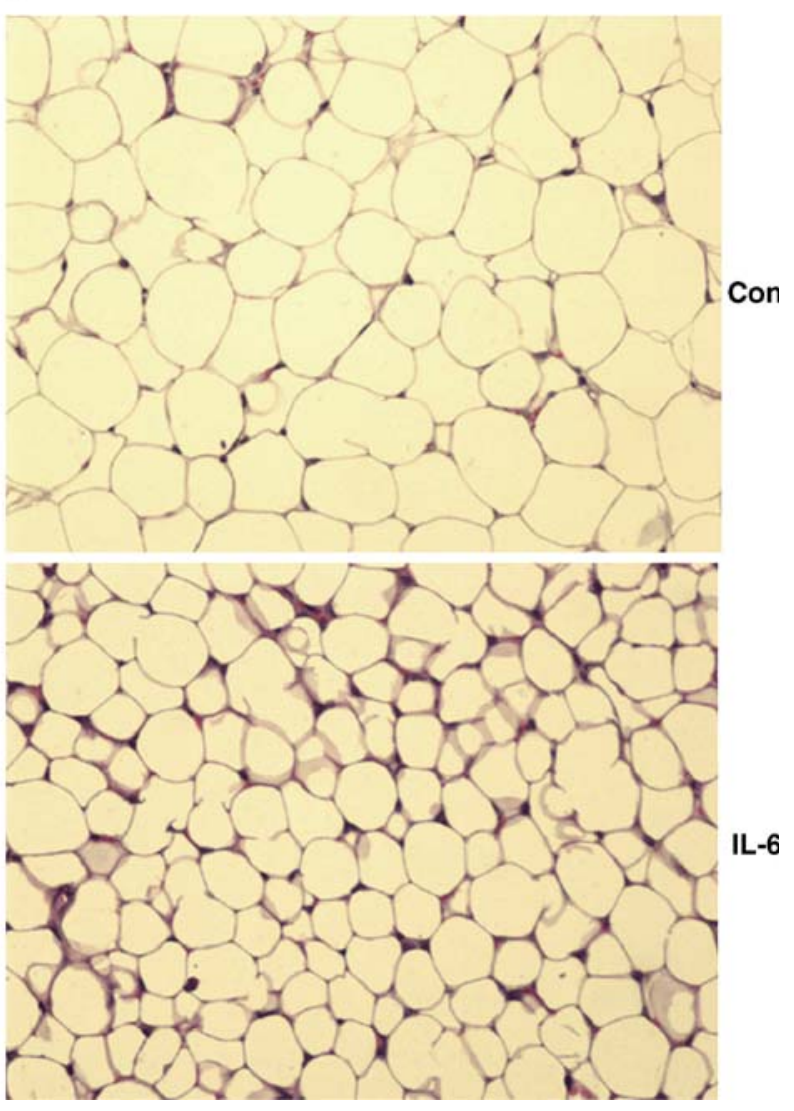

e
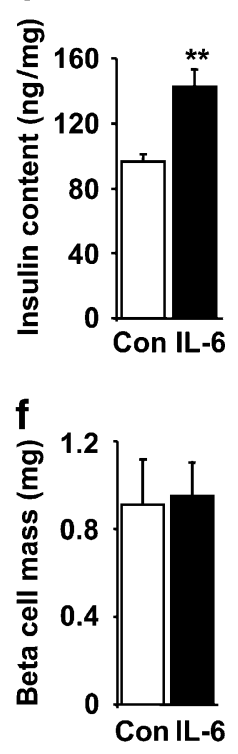

Time ( $\mathrm{min})$

times indicated after glucose injection. Data represent the mean \pm SEM of at least eight animals for each group. ${ }^{* *} p<0.01$. e Pancreatic insulin content of saline solution (control, Con) and CMV-IL-6 (IL-6) electro-transfected mice 7 days after gene transfer. Data represent the mean \pm SEM of at least six animals for each group. ${ }^{* *} p<0.01$. f Islet mass was measured in Con and CMV-IL-6 (IL-6) electro-transfected mice 15 days after gene transfer. Nine pancreatic sections from each individual mouse (three mice per group) were analysed as described in the Methods section 

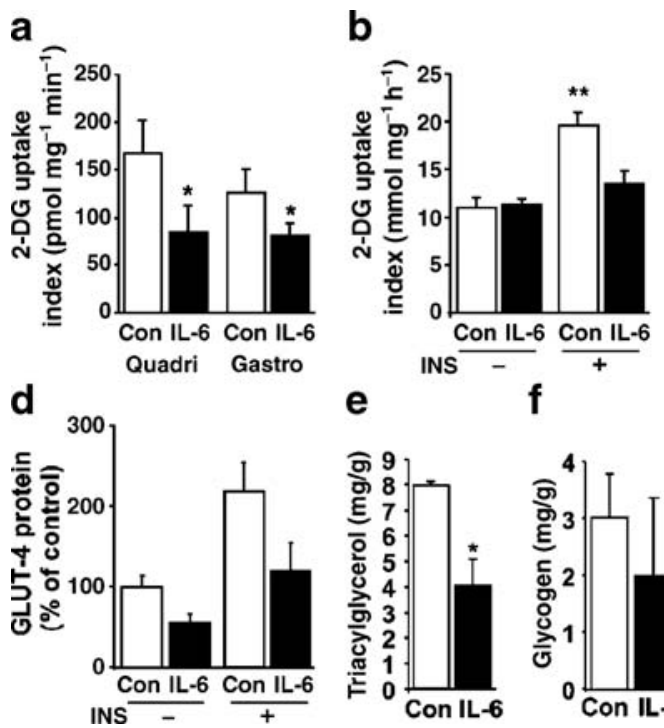

f

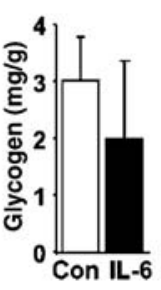

Fig. 4 Skeletal muscle metabolism. a Glucose utilisation index was measured in skeletal muscle (quadriceps and gastrocnemius) of fed control (Con) and CMV-IL-6 (IL-6) electro-transfected mice 15 days after gene transfer. Results are means \pm SEM of four animals for each group. b Glucose uptake ex vivo in soleus muscle and (c, d) GLUT-4 content in plasma membranes in the absence or presence of insulin,

showed that infiltrated cells around centrolobular veins express the common leucocyte CD45 cell surface antigen (Fig. 6b). However, the infiltrated cells were not positive for $\mathrm{F} 4 / 80$, whereas the number of cells was increased (Fig. 6c,e). Acidic phosphatase activity was also increased, indicating a higher macrophagic activity of these cells
C

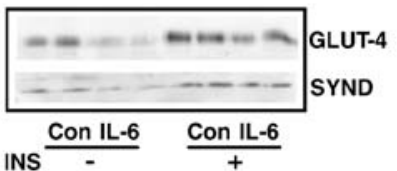

g

h

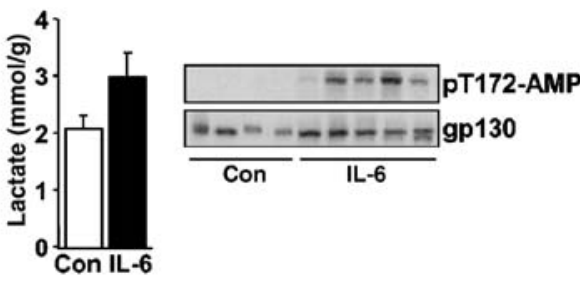

with syndecan (Synd) used as a loading control (c). e Triacylglycerol, f glycogen and $\mathbf{g}$ lactate concentrations in skeletal muscle extracts were measured as described in the Methods section. Results are means \pm SEM of at least six animals for each group. ${ }^{* *} p<0.01$. h pAMPK and gp130 in skeletal muscle of four fed control (Con) and five CMVIL-6 electro-transfected mice

(Fig. 6d). All these results indicate that the infiltrate was not composed of macrophages, but that IL- 6 may induce an increase in Küpffer cell number (positive for F4/80 but not for CD11b). Moreover, the nuclear morphology of infiltrated cells suggests that these cells are mainly neutrophils together with some lymphocytes.
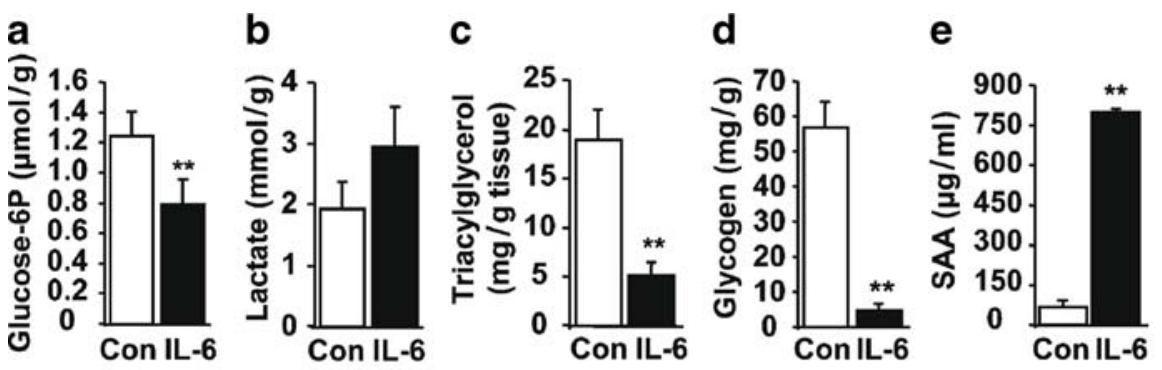

\section{f}
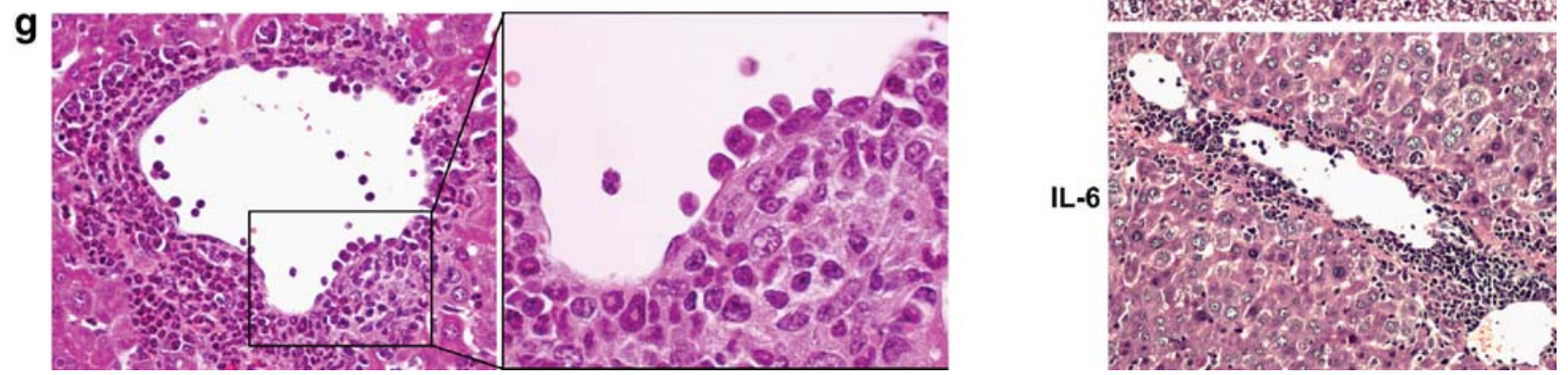

Fig. 5 Liver metabolism and inflammation. a Glucose 6-phosphate (6P), b lactate, $\mathbf{c}$ triacylglycerol and $\mathbf{d}$ glycogen content of liver from fed control (Con) and CMV-IL-6 (IL-6) electro-transfected mice 30 days after gene transfer. Concentrations in liver extracts were measured as described in the Methods section. Results are means \pm SEM of at least six animals for each group. ${ }^{* *} p<0.01$. e Serum amyloid A (SAA) levels were measured in serum from fed Con and
CMV-IL-6 (IL-6) electro-transfected mice 15 days after gene transfer. Results are means \pm SEM of at least ten animals for each group. ${ }^{* *} p<$ 0.01. f Representative sections of liver from Con and IL-6 mice after haematoxylin/eosin staining. Original magnification $\times 10$. g Representative sections of liver from IL-6 mice after haematoxylin/eosin staining showing the perivascular infiltration of inflammatory cells. Original magnification $\times 20$ and $\times 40$ 
a

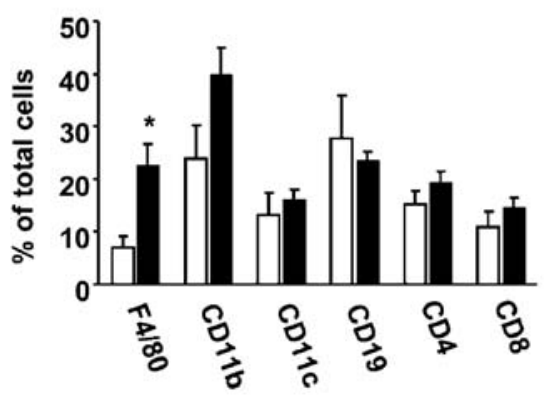

b

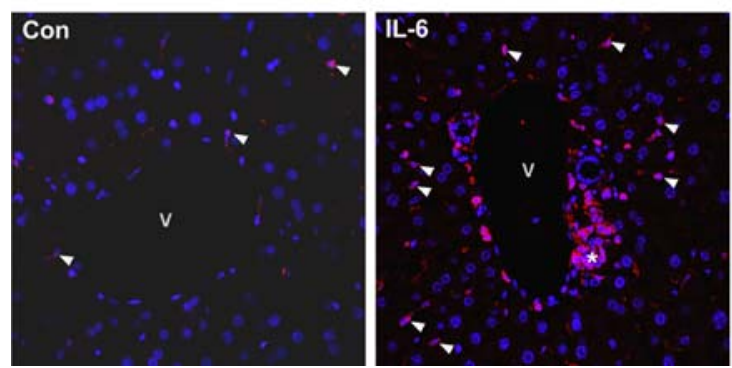

Fig. 6 Characterisation of the inflammatory infiltrate in liver. a Flow cytometry (FACS) analysis was performed as indicated in the Methods section. Results are means \pm SEM of four animals for each group. White columns, control; black columns, IL-6-treated. ${ }^{*} p<0.05$. b Sections of liver from control and IL-6-treated mice 15 days after electro-transfer were subjected to immunostaining. Anti-CD45 was

Altered gene expression levels in IL6 mice To address the mechanisms for these long-term effects of IL-6, we examined the expression of several genes in the skeletal muscle, adipose tissue and liver.

As shown in Table 1, there was a marked increase in the IL-6 mice (relative to controls) in Il6 and its receptor as well as in Socs 3 mRNA levels in the skeletal muscle, while Socs 1 was unchanged. Glut4 (also known as Slc2a4) was decreased, which is consistent with the decreased GLUT-4 protein content (Fig. 4c). The adiponectin receptors 1 and 2 were significantly decreased while Ucp 2 was increased. Several mitochondrial genes (cytochrome C, Cox2 [also known as $m t-C o 2]$, beta-ATP synthase and $m t-T f a$ [also known as Tfam]) were decreased, and PGClalpha (also known as Ppargcla) was also significantly deceased (data not shown).

In contrast, there were no significant changes in the adipose tissue, barring leptin, where a significant reduction was seen (data not shown). This is probably due to the high local concentrations of IL-6 in the adipose tissue [5], since this site is a major producer of IL-6 and is consistent with the concept that IL-6 is mainly a paracrine regulator in the adipose tissue [5].

Pepck and fatty acid synthase were markedly decreased in the liver (Table 1). Furthermore, Il6 and Socs3 were
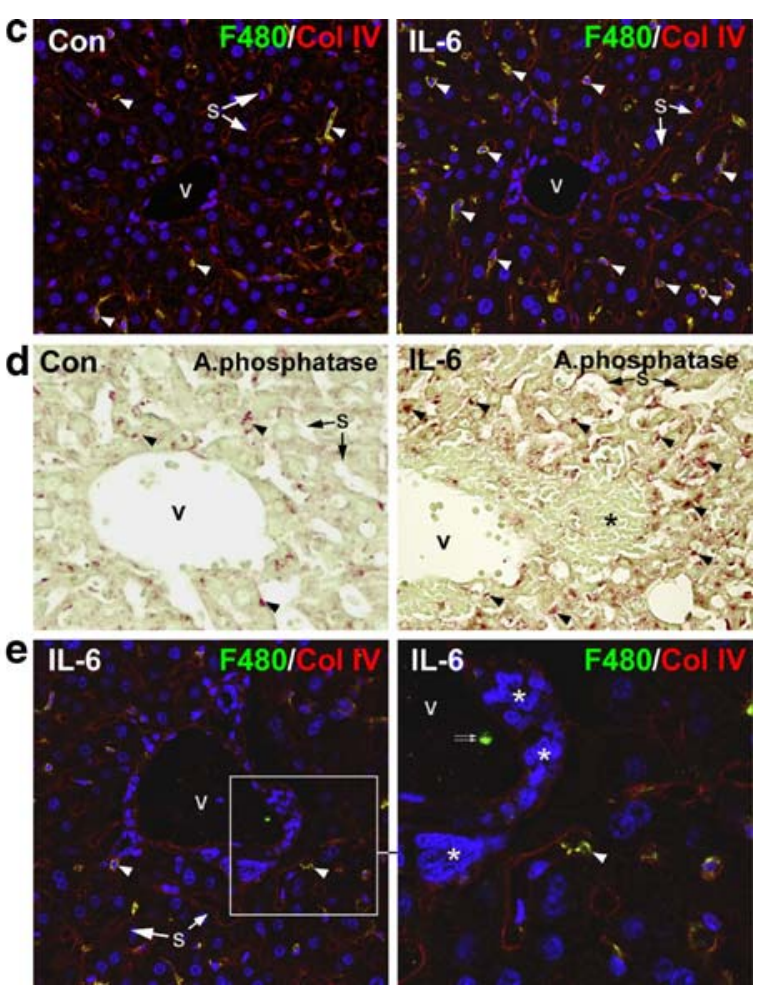

used as a primary antibody. c, e Representative immunohistochemistry from liver sections. Anti-F4/80 was used as a primary antibody. d Macrophage activity was assessed by staining for acidic (a) phosphatase. v, centrolobular vein; arrowheads, Küpffer cells; double arrow, monocytes; *, infiltrated cells; s, sinusoids

increased together with several markers of inflammation, including Saa, Tnf-alpha (also known as Tnf) and Mcp-1 (also known as Ccl2). PGClalpha and adiponectin receptor 2 were also significantly decreased.

\section{Discussion}

IL-6 is a cytokine with pleiotrophic effects due to the ubiquitous presence of IL- 6 receptors, either cellular or soluble, making most cells potential target cells. Thus, it is not surprising that many different effects of IL-6 have been reported. It is a proinflammatory cytokine in most cells, but it may also be anti-inflammatory in some cells and antagonise the effect of TNF-alpha [38]. IL-6 is proinflammatory in both the liver and adipose cells [12-14, 39] and has repeatedly been shown to induce insulin resistance in both cells $[6,11-14]$. This effect is, in part, due to the induction of suppressor of cytokine signalling 3 (SOCS-3), which binds to and impairs activation of the insulin receptor and IRS-1 in response to insulin [40, 41]. In addition, IL-6 reduces the production of IRS- 1 and GLUT- 4 protein in the adipose cells [6] and also impairs the transcriptional 
activation of many genes such as IRS-1, GLUT-4, LPL and adiponectin, while it activates cytokine expression and serum amyloid A [6, 12, 13, 39].

In contrast to the effects in liver and adipose cells, positive effects have been reported in skeletal muscle in terms of increasing glucose uptake in short-term experiments [17-19]. However, the overall importance of these short-term experimental studies is unclear considering that IL-6 levels are chronically elevated in obesity, mainly due to increased production by the adipose tissue and the enlarged fat cells [5, 42].

The present study was designed to clarify the effects of chronically increased IL- 6 production by the skeletal muscles. It should be emphasised that the circulating IL-6 levels were elevated to levels seen in chronic inflammation rather than those following normal exercise. Thus, the results may not necessarily reflect effects seen under more modest and transient elevations. However, the phenotype of the mice, seen already after 1 week, was surprising. Clearly, the animals lost body weight and fat, which is consistent with the lower circulating leptin levels. However, the lower adiponectin levels were unexpected in view of the reduced body fat and supports the notion of an inhibitory effect of IL-6 on adiponectin production by the fat cells $[5,13,39]$. The reduction in body weight is due to increased energy expenditure, which is consistent with other studies, in which, however, it was suggested to be exclusively due to a central effect of IL-6 requiring an intracerebral injection $[20,22]$. Our findings clearly show that this effect is also seen when the circulating IL-6 levels are chronically increased. However, we cannot exclude the possibility that IL-6 may cross the blood-brain barrier when chronically elevated.

The most surprising effect of IL-6 overproduction was the marked increase in circulating insulin levels combined with hypoglycaemia. Analyses of the islets suggest that this was due to an increased cellular insulin content. Although the effect of IL- 6 on insulin release has not been much studied, a few previous publications have found that IL-6 can increase insulin synthesis and secretion [43, 44] and even protect the beta cells [45]. In contrast, it was recently reported that IL-6 reduced insulin secretion at low (3.3 $\mathrm{mmol} / \mathrm{l})$ but not at high $(11.1 \mathrm{mmol} / \mathrm{l})$ glucose concentrations in isolated islets from some animal models [46]. The reason for this discrepancy is currently unclear. Interestingly, it was recently reported that circulating IL-6 levels correlated positively with insulin levels in man and that this was unrelated to degree of insulin resistance [47]. One possible mechanism for this could be AMPK activation by IL-6. AMPK activation has been shown to increase insulin secretion in mouse islets [48]. Also other aspects of the phenotype seen in the mice overexpressing Il6 are consistent with increased AMPK activation in several organs. Overproduction of AMPK in the liver produced mild hypoglycaemia due to reduced gluconeogenesis, including reduced Pepck expression [49] as also seen in our mice. However, the insulin levels were lower in those mice in contrast to our findings, where they were inappropriately high, supporting the notion of a stimulating effect of IL-6 on the islet beta cells. However, we cannot exclude the possibility that the effect of IL- 6 may be indirect.

Several additional findings support the idea that gluconeogenesis was reduced in the mice overexpressing $I l 6$, since, in addition to low Pepck expression in the liver, the animals were hypoglycaemic and hyperinsulinaemic. Furthermore, injection of a bolus dose of insulin produced prolonged hypoglycaemia in the IL-6 mice, without any increase in glucose levels over $60 \mathrm{~min}$, while the wild-type mice rapidly recovered over the same period (ESM Fig. 1). Although direct AMPK activation by IL-6 in the liver may contribute to this, the most important primary effect is likely to be hyperinsulinaemia.

Interestingly, glucose uptake by the skeletal muscles was reduced both in vivo and ex vivo in IL-6 mice, probably due to lower GLUT-4 content, since no apparent defect was seen in the ability of insulin to activate PKB/Akt. Further studies are required to clarify whether this is a direct effect of chronically elevated IL-6 levels or secondary to concomitant hyperinsulinaemia and hypoglycaemia.

An additional interesting phenotype developed by $I l 6$ overexpression in the skeletal muscle was a marked inflammation in the liver, shown as both elevated circulating levels of serum amyloid A cluster as well as markedly increased gene expression of Saa, Tnf-alpha, Il6 and Socs3. This constellation should also reduce insulin sensitivity in the liver, but this was obviously overcome by the marked hyperinsulinaemia. Interestingly, however, these mice did not develop fatty liver, which has been seen in mice specifically overproducing SOCS3 or AMPK respectively in the liver $[49,50]$. In our mice, it is likely that the marked reduction in adipose tissue mass and circulating NEFA levels, combined with increased lipid oxidation and AMPK activation in skeletal muscle, prevented this effect. However, these data emphasise that inflammation in the liver does not require an increased accumulation of liver fat, but that it may also be induced by a chronic systemic inflammation. In fact, the triacylglycerol levels were significantly lower in the IL-6 mice, consistent with an increased lipid oxidation and decreased circulating triacylglycerol levels. Thus, it is possible that the elevated IL-6 levels in obesity may directly contribute to the development of liver inflammation and non-alcoholic steato-hepatitis frequently seen in this condition.

In conclusion, chronic overproduction of IL-6 in the skeletal muscle produces a clear phenotype including 
reduced body fat, hypoadiponectaemia, liver inflammation, inappropriate hyperinsulinaemia and hypoglycaemia. Thus, the pleiotrophic effects of chronically elevated IL-6 levels preclude any obvious usefulness in the treatment of obesity or its associated metabolic complications in man, despite the fact that weight reduction may be expected. Furthermore, the effects of chronically elevated IL-6 levels on insulin secretion and liver inflammation deserve further attention.

Acknowledgements This work was supported by the European Community's FP6 EUGENE2 (LSHM-CT-2004-512013), the Novo Nordisk Foundation, the Swedish Diabetes Association, the Swedish Medical Research Council, the Foundation for Strategic Research, the Torsten and Ragnar Söderberg Foundation, the Plan Nacional de I+D+I (SAF2005-01262) and the Instituto de Salud Carlos III (PI 051586 and PI 051600).

Duality of interest The authors declare that there is no duality of interest associated with this manuscript.

\section{References}

1. Naka T, Nishimoto N, Kishimoto T (2002) The paradigm of IL-6: from basic science to medicine. Arthritis Res 4(Suppl 3):S233S242

2. Kamimura D, Ishihara K, Hirano T (2003) IL-6 signal transduction and its physiological roles: the signal orchestration model. Rev Physiol Biochem Pharmacol 149:1-38

3. Pickup JC (2004) Inflammation and activated innate immunity in the pathogenesis of type 2 diabetes. Diabetes Care 27:813-823

4. Kristiansen OP, Mandrup-Poulsen T (2005) Interleukin-6 and diabetes: the good, the bad, or the indifferent? Diabetes 54(Suppl 2): S114-S124

5. Sopasakis VR, Sandqvist M, Gustafson B et al (2004) High local concentrations and effects on differentiation implicate interleukin6 as a paracrine regulator. Obes Res 12:454-460

6. Rotter V, Nagaev I, Smith U (2003) Interleukin-6 (IL-6) induces insulin resistance in 3T3-L1 adipocytes and is, like IL-8 and tumor necrosis factor-alpha, overexpressed in human fat cells from insulin-resistant subjects. J Biol Chem 278:45777-45784

7. Bastard JP, Maachi M, Van Nhieu JT et al (2002) Adipose tissue IL-6 content correlates with resistance to insulin activation of glucose uptake both in vivo and in vitro. J Clin Endocrinol Metab 87:2084-2089

8. Kern PA, Ranganathan S, Li C, Wood L, Ranganathan G (2001) Adipose tissue tumor necrosis factor and interleukin- 6 expression in human obesity and insulin resistance. Am J Physiol Endocrinol Metab 280:E745-E751

9. Cardellini M, Perego L, D'Adamo M et al (2005) C-174G polymorphism in the promoter of the interleukin-6 gene is associated with insulin resistance. Diabetes Care 28:2007-2012

10. Carey AL, Bruce CR, Sacchetti M et al (2004) Interleukin-6 and tumor necrosis factor-alpha are not increased in patients with Type 2 diabetes: evidence that plasma interleukin-6 is related to fat mass and not insulin responsiveness. Diabetologia 47:1029-1037

11. Senn JJ, Klover PJ, Nowak IA, Mooney RA (2002) Interleukin-6 induces cellular insulin resistance in hepatocytes. Diabetes 51:3391-3399

12. Lagathu C, Bastard JP, Auclair M, Maachi M, Capeau J, Caron M (2003) Chronic interleukin-6 (IL-6) treatment increased IL-6 secretion and induced insulin resistance in adipocyte: prevention by rosiglitazone. Biochem Biophys Res Commun 311:372-379

13. Fasshauer M, Kralisch S, Klier M et al (2003) Adiponectin gene expression and secretion is inhibited by interleukin-6 in 3T3-L1 adipocytes. Biochem Biophys Res Commun 301:1045-1050

14. Klover PJ, Zimmers TA, Koniaris LG, Mooney RA (2003) Chronic exposure to interleukin-6 causes hepatic insulin resistance in mice. Diabetes 52:2784-2789

15. Kim HJ, Higashimori T, Park SY et al (2004) Differential effects of interleukin- 6 and-10 on skeletal muscle and liver insulin action in vivo. Diabetes 53:1060-1067

16. Kelly M, Keller C, Avilucea PR et al (2004) AMPK activity is diminished in tissues of IL-6 knockout mice: the effect of exercise. Biochem Biophys Res Commun 320:449-454

17. Al-Khalili L, Bouzakri K, Glund S, Lonnqvist F, Koistinen HA, Krook A (2006) Signaling specificity of interleukin-6 action on glucose and lipid metabolism in skeletal muscle. Mol Endocrinol 20:3364-3375

18. Carey AL, Steinberg GR, Macaulay SL et al (2006) Interleukin-6 increases insulin-stimulated glucose disposal in humans and glucose uptake and fatty acid oxidation in vitro via AMP-activated protein kinase. Diabetes 55:2688-2697

19. Weigert C, Hennige AM, Brodbeck K, Haring HU, Schleicher ED (2005) Interleukin-6 acts as insulin sensitizer on glycogen synthesis in human skeletal muscle cells by phosphorylation of Ser473 of Akt. Am J Physiol Endocrinol Metab 289:E251-E257

20. Wallenius V, Wallenius K, Ahren B et al (2002) Interleukin-6deficient mice develop mature-onset obesity. Nat Med 8:75-79

21. Di Gregorio GB, Hensley L, Lu T, Ranganathan G, Kern PA (2004) Lipid and carbohydrate metabolism in mice with a targeted mutation in the IL- 6 gene: absence of development of age-related obesity. Am J Physiol Endocrinol Metab 287:E182-E187

22. Wallenius K, Wallenius V, Sunter D, Dickson SL, Jansson JO (2002) Intracerebroventricular interleukin-6 treatment decreases body fat in rats. Biochem Biophys Res Commun 293:560-565

23. Strassmann G, Fong M, Kenney JS, Jacob CO (1992) Evidence for the involvement of interleukin 6 in experimental cancer cachexia. J Clin Invest 89:1681-1684

24. Greenberg AS, Nordan RP, McIntosh J, Calvo JC, Scow RO, Jablons D (1992) Interleukin 6 reduces lipoprotein lipase activity in adipose tissue of mice in vivo and in 3T3-L1 adipocytes: a possible role for interleukin 6 in cancer cachexia. Cancer Res 52:4113-4116

25. Lyngso D, Simonsen L, Bulow J (2002) Metabolic effects of interleukin-6 in human splanchnic and adipose tissue. J Physiol 543:379-386

26. Trujillo ME, Sullivan S, Harten I, Schneider SH, Greenberg AS, Fried SK (2004) Interleukin-6 regulates human adipose tissue lipid metabolism and leptin production in vitro. J Clin Endocrinol Metab 89:5577-5582

27. Pedersen BK, Steensberg A, Schjerling P (2001) Musclederived interleukin-6: possible biological effects. J Physiol 536:329-337

28. Febbraio MA, Pedersen BK (2002) Muscle-derived interleukin-6: mechanisms for activation and possible biological roles. Faseb $\mathrm{J}$ 16:1335-1347

29. Febbraio MA, Steensberg A, Keller C et al (2003) Glucose ingestion attenuates interleukin-6 release from contracting skeletal muscle in humans. J Physiol 549:607-612

30. Hiscock N, Fischer CP, Sacchetti M, van Hall G, Febbraio MA, Pedersen BK (2005) Recombinant human interleukin-6 infusion during low-intensity exercise does not enhance whole body lipolysis or fat oxidation in humans. Am J Physiol Endocrinol Metab 289:E2-E7

31. McMahon JM, Signori E, Wells KE, Fazio VM, Wells DJ (2001) Optimisation of electrotransfer of plasmid into skeletal muscle by 
pretreatment with hyaluronidase-increased expression with reduced muscle damage. Gene Ther 8:1264-1270

32. Carr TP, Andresen CJ, Rudel LL (1993) Enzymatic determination of triglyceride, free cholesterol, and total cholesterol in tissue lipid extracts. Clin Biochem 26:39-42

33. Ferre T, Riu E, Bosch F, Valera A (1996) Evidence from transgenic mice that glucokinase is rate limiting for glucose utilization in the liver. Faseb J 10:1213-1218

34. Ferre P, Leturque A, Burnol AF, Penicaud L, Girard J (1985) A method to quantify glucose utilization in vivo in skeletal muscle and white adipose tissue of the anaesthetized rat. Biochem J 228:103-110

35. Tanti JF, Rochet N, Gremeaux T, Van Obberghen E, Le MarchandBrustel Y (1989) Insulin-stimulated glucose transport in muscle. Evidence for a protein-kinase-C-dependent component which is unaltered in insulin-resistant mice. Biochem J 258:141-146

36. George M, Ayuso E, Casellas A, Costa C, Devedjian JC, Bosch F (2002) Beta cell expression of IGF-I leads to recovery from type 1 diabetes. J Clin Invest 109:1153-1163

37. Rotter Sopasakis V, Larsson BM, Johansson A, Holmang A, Smith U (2004) Short-term infusion of interleukin-6 does not induce insulin resistance in vivo or impair insulin signalling in rats. Diabetologia 47:1879-1887

38. Pedersen BK, Steensberg A, Keller P et al (2003) Muscle-derived interleukin-6: lipolytic, anti-inflammatory and immune regulatory effects. Pflugers Arch 446:9-16

39. Gustafson B, Smith U (2006) Cytokines promote Wnt signaling and inflammation and impair the normal differentiation and lipid accumulation in 3T3-L1 preadipocytes. J Biol Chem 281:9507-9516

40. Emanuelli B, Peraldi P, Filloux C et al (2001) SOCS-3 inhibits insulin signaling and is up-regulated in response to tumor necrosis factor-alpha in the adipose tissue of obese mice. J Biol Chem 276:47944-47949

41. Senn JJ, Klover PJ, Nowak IA et al (2003) Suppressor of cytokine signaling-3 (SOCS-3), a potential mediator of interleukin-6-dependent insulin resistance in hepatocytes. J Biol Chem 278:13740-13746
42. Mohamed-Ali V, Goodrick S, Rawesh A et al (1997) Subcutaneous adipose tissue releases interleukin-6, but not tumor necrosis factor-alpha, in vivo. J Clin Endocrinol Metab 82:41964200

43. Sandler S, Bendtzen K, Eizirik DL, Welsh M (1990) Interleukin-6 affects insulin secretion and glucose metabolism of rat pancreatic islets in vitro. Endocrinology 126:1288-1294

44. Shimizu H, Ohtani K, Kato Y, Mori M (2000) Interleukin-6 increases insulin secretion and preproinsulin mRNA expression via $\mathrm{Ca}^{2+}$-dependent mechanism. J Endocrinol 166:121-126

45. Choi SE, Choi KM, Yoon IH et al (2004) IL-6 protects pancreatic islet beta cells from pro-inflammatory cytokines-induced cell death and functional impairment in vitro and in vivo. Transpl Immunol 13:43-53

46. Handschin C, Choi CS, Chin S et al (2007) Abnormal glucose homeostasis in skeletal muscle-specific PGC-1alpha knockout mice reveals skeletal muscle-pancreatic beta cell crosstalk. J Clin Invest 117:3463-3474

47. Andreozzi F, Laratta E, Cardellini M et al (2006) Plasma interleukin-6 levels are independently associated with insulin secretion in a cohort of Italian-Caucasian nondiabetic subjects. Diabetes 55:2021-2024

48. Wang CZ, Wang Y, Di A et al (2005) 5-amino-imidazole carboxamide riboside acutely potentiates glucose-stimulated insulin secretion from mouse pancreatic islets by KATP channeldependent and-independent pathways. Biochem Biophys Res Commun 330:1073-1079

49. Foretz M, Ancellin N, Andreelli F et al (2005) Short-term overexpression of a constitutively active form of AMP-activated protein kinase in the liver leads to mild hypoglycaemia and fatty liver. Diabetes 54:1331-1339

50. Ueki K, Kondo T, Tseng YH, Kahn CR (2004) Central role of suppressors of cytokine signaling proteins in hepatic steatosis, insulin resistance, and the metabolic syndrome in the mouse. Proc Natl Acad Sci USA 101:10422-10427 